\title{
perifèria
}

Número 18 (2), desembre 2013

http://revistes.uab.cat/periferia

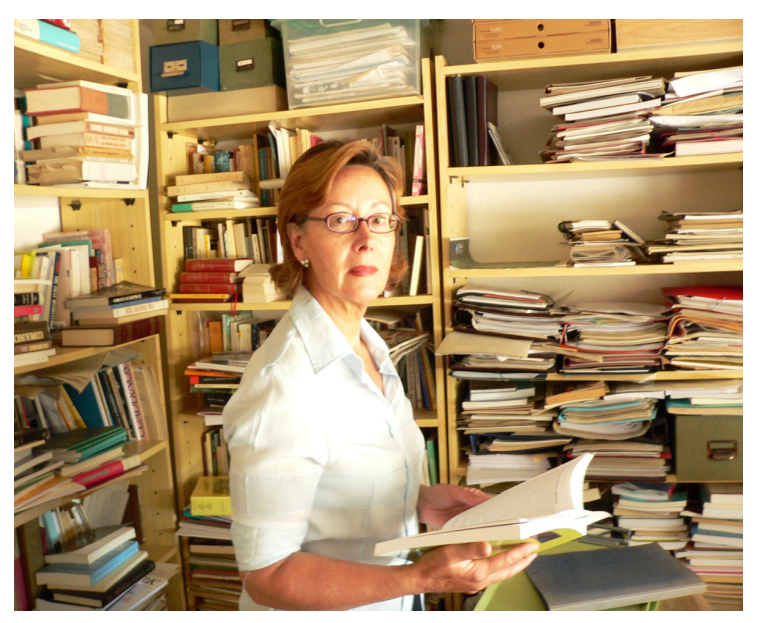

\section{Del bilinguiismo a la bioética: Maria Jesús Buxó, ejemplo de antropología polivalente}

Autoras: Amunarriz del Río, Elena; Brito Fuentes, Carla; Villar Romón,

Carolina. Universidad Autónoma de Barcelona

Directora: Montserrat Clua Fainé ${ }^{1}$

\section{Resumen}

En esta ocasión el Projecte Entrevistas se ha acercado a la biografía de Maria Jesús Buxó, una de las primeras discípulas de Claudi Esteva Fabregat, pionera en antropología aplicada en España y un referente imprescindible actualmente en el debate sobre ética y bioética. La amplia trayectoria temática y académica de Buxó sorprende por su versatilidad, capaz de trabajar temas aparentemente tan distintos como el bilingüismo, nuevas tecnologías, antropología aplicada, género, la fertilidad en las mujeres obreras catalanas o el estudio de los jardines. Sin duda, se trata de todo un referente para la antropología catalana.

\section{Resum}

En aquesta ocasió el Projecte Entrevistes s'ha acostat a la biografia de Maria Jesús Buxó, una de les deixebles de Claudi Esteva Fabregat, pionera en antropologia aplicada a Espanya i un referent imprescindible en el debat actual

\footnotetext{
1 Enviar correspondencia a: Montserrat.clua@uab.cat
} 


\section{perifèria}

Número 18 (2), desembre 2013

http://revistes.uab.cat/periferia

sobre ètica i bioètica. La seva àmplia trajectòria temàtica i acadèmica sorprèn per la seva versatilitat, capaç de treballar temes aparentment tan diversos com el bilingüisme, les noves tecnologies, el gènere, la fertilitat de les dones obreres catalanes o l'estudi dels jardins. Sens dubte estem davant de tot un referent per a l'antropologia catalana.

\section{Pregunta: Buenos días y muchas gracias por atendernos. La primera pregunta que nos planteábamos es: ¿cómo llegó usted a la antropología y, en concreto, a la Universidad de Barcelona?}

Maria Jesús Buxó: Son dos vías las que me llevan a la antropología. Una vía es doméstica: mi familia tenía muy buena relación de amistad con el arqueólogo-prehistoriador Lluís Pericot, quién conocía mi interés por la lingüística clásica y me sugirió estudiar Historia Antigua. Por otro lado, mi madre tenía un hermano que era simpatizante de la Fabian Society, era médico y farmacéutico y tenía contactos que le permitían escribir en alguna revista local inglesa. ¿Sabéis que es un fabiano ${ }^{2}$ ? Era un movimiento socialista con toques utópicos y algunos de sus miembros sentaron las bases de la London School of Economics: los Webb, Wallas, Shaw. Eran todos, especialmente escritores, interesados por la reforma social, como H.G. que lo plantea desde la ciencia ficción, "The time machine". Y esa conjunción de intelectuales y escuela hoy se conoce más por la llamada "Tercera vía" ideada por A. Giddens y supuestamente llevada a término por Tony Blair. En casa había libros de Wells y en particular el de Grahan Wallas "Human Nature in Politics, un autor que siempre he citado en clase al hablar de la irracionalidad en las decisiones. Entonces mi tío era cercano a los movimientos socialistas británicos, y cercano también a la LSE, por lo que

\footnotetext{
2 La Sociedad Fabiana fundada el 4 de enero de 1884 en Londres, es un movimiento socialista británico cuyo propósito es avanzar en la aplicación de los principios del socialismo democrático mediante reformas graduales. Es también conocida por formar los cimientos de lo que más tarde sería el Partido Laborista británico.
} 


\section{perifèria}

Número 18 (2), desembre 2013

http://revistes.uab.cat/periferia

mi madre siempre hablaba en casa de estos movimientos y de la antropología.

En definitiva, entre mi madre y Lluís Pericot estudié en la UB. No había muchas opciones en la época y la más próxima a mis intereses era Historia Antigua, enfoqué Próximo Oriente y magníficos profesores (Dr. Bejarano, Dra. Muñoz), pronto me iniciaron en el sanscrito y el lineal $B$, pensando en llegar a analizar correspondencias entre reyes Hititas y Hurritas. Una vez dentro de Historia Antigua tuve la suerte de coincidir con una persona que llegó del exilio, que había pasado por Madrid y había fundado una escuela de antropología, que era Claudio Esteva Fabregat. Por aquel entonces él ejercía como profesor en Barcelona impartiendo clases de "Etnología de los pueblos primitivos", además de "Antropología Cultural". En aquella época Esteva tenía un éxito total de alumnos: tenía que dar la clase en el aula magna porque se llenaba a las ocho de la mañana. Y, entre otras sobre etnología andina y azteca, la asignatura que más me interesó fue "Antropología Lingüística". Su magisterio me hizo pasar de la antigüedad clásica a las sociedades contemporáneas, por lo que acabé mi licenciatura en Historia Antigua con una pequeña distinción en antropología, porque por aquel entonces no existía la antropología como licenciatura.

Para seguir estudiando antropología, solicité una beca Fullbright, me presenté a las pruebas de esa comisión, pasé el TOEFL y me dieron a elegir tres universidades norteamericanas. No me costó mucho elegir la universidad porque tenía claro que quería profundizar y realizar mi trabajo de campo sobre problemas relacionados con el bilingüismo y el biculturalismo. $Y$ en este sentido me interesó la Universidad de Nuevo México. Seleccioné con el Dr.Basehart (director del departamento) y el Dr. 


\section{perifèria}

Número 18 (2), desembre 2013

http://revistes.uab.cat/periferia

Spuhler (comité editorial del Annual Review of Anthropology) aquellas asignaturas más cercanas a mis intereses: Sociolinguistics, Neurolinguistics, Language and Thought across cultures, entre otras. Y me examiné de los 38 créditos preparatorios para realizar la tesis doctoral sobre "Antropología del bilingüismo, multilingüismo y variantes de un código" que presenté en la UB en enero de 1975. En mi formación en Barcelona también hubo importantes lingüistas como el Dr. Marsá (gramática generativa) y el joven Dr. Serrano que nos enseñaba semántica y lingüística matemática. Y antropólogos físicos, como el Dr. Pons y el Dr. Valls, cuyas enseñanzas sirvieron para que pudiera cursar con mas facilidad Biological Anthropology and Phisiological Anthropology en el departamento de antropología de la UNM. Y a esa distancia de Barcelona puedo contar la anécdota que aconteció cuando cursé la asignatura de Cultural Ecology, pues el primer libro que me recomendaron fue "Perspectives in Ecological Theory" (1968) del Dr.Margalef.

P: Nos hemos estado informando, hemos estado leyendo artículos suyos, libros, y hemos encontrado una gran influencia de Claudio Esteva Fabregat en sus obras. ¿Se sentiría usted cómoda siendo denominada discípula del mismo? ¿Qué es lo que le ha aportado Claudio Esteva Fabregat a su aproximación a la antropología?

B: Estaría absolutamente cómoda siendo denominada discípula de él. A mi regreso de USA seguí colaborando con el Dr. Esteva en el Centro de Etnología Peninsular (CSIC), como becaria y con un equipo de antropólogos egresados también de la UB, trabajamos en la formación de una biblioteca de etnología y coordinábamos la publicación de la revista Ethnica. Porque para él era muy importante que fundamentásemos nuestro conocimiento en

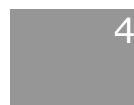




\section{perifèria}

Número 18 (2), desembre 2013

http://revistes.uab.cat/periferia

una biblioteca bien establecida, y no había en Barcelona en aquella época ninguna biblioteca de etnología ni antropología. Fue así como el profesor Esteva nos preparaba como antropólogos: mientras preparábamos la biblioteca hacíamos toda nuestra formación general, y formábamos parte de proyectos de investigación dirigidos por el Dr. Esteva en Cataluña e Hispanoamérica. Ahí empecé los trabajos de campo.

Por lo tanto, Esteva influyó en mi formación teórica y en la manera de realizar el trabajo de campo. Su aportación clave se orientaba a cuidar y valorar en sobremanera la observación; siempre nos daba a entender que teníamos que comportarnos como naturalistas a la vez que acentuaba el sentido creativo de la labor etnográfica. Él siempre decía que el trabajo de campo no es simplemente ir a observar a otra cultura y registrar información, sino contribuir a crear datos etnográficos. $Y$ a esa responsabilidad añadía que no había que imponer a priori el marco teórico a los datos, sino a posteriori para analizar e interpretar los datos obtenidos en el terreno. Sin duda la metodología estaba marcada por el funcionalismo, lo cual nos obligaba a pensar la estrategia de campo en términos de necesidades y propósito. $\mathrm{Y}$, además, siempre en el amplio marco de referencia de las cuatro ramas de la escuela boasiana de su formación norteamericana: la etnología, la lingüística, la arqueología y la antropología física.

Estas cuatro ramas en mi caso también las cumplía, porque al hacer Historia Antigua hice arqueología. Llegué incluso a hacer excavación en el poblado ibérico de Ullastret. Mi formación de lingüista la hice también dentro de la licenciatura de Historia Antigua. $Y$ también hice algo de antropología física, lo cual me ha venido muy bien para la parte final de mi formación, porque en la actualidad estoy trabajando en un Parque Científico 


\section{perifèria}

Número 18 (2), desembre 2013

http://revistes.uab.cat/periferia

y la mayor parte de la gente que trabaja allí son de genética, médicos y biólogos. En definitiva, aquel poco de formación en antropología física que di en Norteamérica, se transformó en antropología biológica y algo de neurolingüística y me sirvió posteriormente.

Por lo tanto, Esteva influyó en mi formación en trabajo de campo: mis primeros trabajos de campo los hice a su lado. Las primeras prácticas de trabajo de campo las hicimos en equipo, algunos distribuidos por pueblos de La Garrotxa (a mí me tocó Tortellà), y luego en el Alto Aragón, en Bielsa, formé parte de un equipo del que todavía recuerdo a Juanjo Pujades y Josefina Roma, entre otros. Posteriormente, como él era americanista, y director en el marco de proyectos con el Instituto de Cooperación Iberoamericana, fuimos a Chincheros (Perú) y Quetzaltenango (Guatemala), en temporadas de verano, una vez concluido el período lectivo en la UB.

Y otra influencia que él me dejó muy importante fue la relevancia de la antropología aplicada. Sin duda su interés por la antropología aplicada despertó también mi preocupación por el sentido pragmático de la antropología y su potencial para plantear propuestas que fueran relevantes en la formulación de problemas públicos, como desarrollé en el ámbito de la seguridad viaria y más tarde en relación con el impacto social y ético de las NT. 


\section{perifèria}

Número 18 (2), desembre 2013

http://revistes.uab.cat/periferia

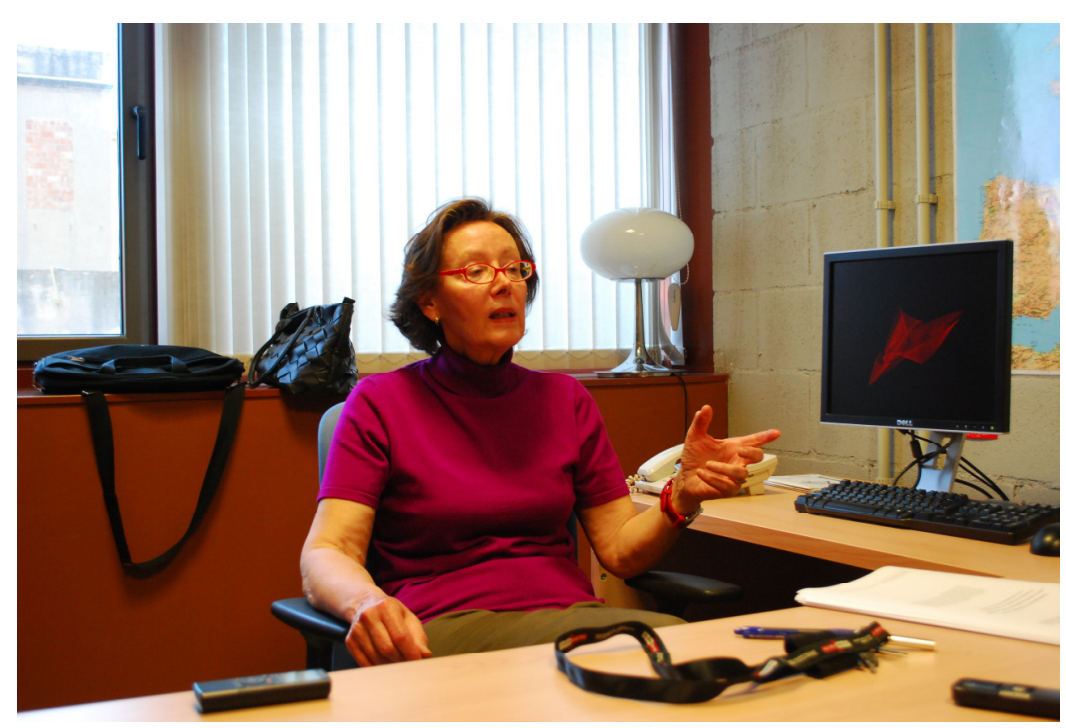

P: Nos preguntábamos si aparte de Claudio Esteva Fabregat nos podría nombrar algún autor o autora que también haya marcado de una manera considerable su carrera profesional.

B: Pues una persona a la que tengo un gran afecto intelectual es el doctor Carmelo Lisón Tolosana. No ha sido mi maestro como fue Claudio Esteva, pero he podido compartir su saber en numerosas reuniones y seminarios, así como en lecturas de tesis doctorales. Apreciar los matices de su esplendida formación anglosajona, su magisterio en la formulación y en el debate de ideas permite siempre extraer lecciones de gran interés y utilidad para profundizar en la investigación, especialmente cuando se trata de debatir etnografías difíciles por confluir la distancia de la complejidad imaginaria y la proximidad territorial, como en Galicia. Y, en el ámbito de la investigación no quisiera dejar de mencionar al Dr. Davydd Greenwood que siempre ha colaborado generosamente en seminarios y conferencias en España y en Cornell University, cuestionando y abriendo territorios conceptuales sobre la participación y la propiedad de los problemas. 
perifèria

Número 18 (2), desembre 2013

http://revistes.uab.cat/periferia

P: Pues la siguiente pregunta va por aquí: durante los años '70, cuando usted estaba formándose, la antropología española también estaba empezando su institucionalización mediante estos dos modelos distintos entre la antropología cultural norteamericana que introdujo Esteva, y una antropología social británica que aportó la experiencia de Lisón en Oxford. ¿Cómo vivió el hecho de que al final se instaurase en España más bien el modelo Lisón, teniendo en cuenta que su formación fue bajo el modelo americanista de Esteva?

B: Vamos a ver, me parece que más que una "guerra" entre escuelas y en la formación de los departamentos, se enfrentaron nombres $y$ actitudes ideológicas que rara vez culminaron en desarrollos teóricos, más bien quedaron en habladurías de corredor. Indudablemente el hecho de que el doctor Lisón estuviese en Madrid, la proximidad con el poder sociológico, debió influir en que la antropología en España se denominase institucionalmente Antropología Social. Si Esteva hubiese seguido dirigiendo la Escuela de Antropología en Madrid, quizás hubiese sido otro el tempo y la manera de instituir los estudios de antropología y se habría llamado Antropología Cultural. A lo largo del tiempo, los diferentes matices han servido para poder contrastar mejor el quehacer etnográfico y las elaboraciones teóricas, como también ocurre en otros países y departamentos. Incluso esto se nota por el hecho de que algunos han optado por usar ambas: social y cultural, como es el caso de la UB, mientras en la Universidad de Sevilla, bajo el magisterio del Dr. Jiménez y el período de Alcina Franch, siguió la denominación de cultural. Más allá de personalismos, si acaso este conflicto de denominaciones y enfoques lastró otros intereses, fue en las segundas generaciones que tenían que situarse 


\section{perifèria}

Número 18 (2), desembre 2013

http://revistes.uab.cat/periferia

en las instituciones y para ello hicieron uso de banderolas partidistas. Una vez colocados, las pugnas pronto se disolvieron en cotilleos.

\section{P: Pasemos a su trayectoria a partir de la publicación de su tesis en el año 1975 en la Universidad de Barcelona, dentro del campo de la lingüística. Nos preguntábamos qué le llevó a enfocar su estudio dentro de la lingüística.}

B: Yo creo que te lo contesté antes: por mi formación inicial en lingüística, siempre me interesó el trasfondo cultural de las lenguas, lo cual ocurre cuando se estudian lenguas clásicas, sanscrito, latín, griego, que no es posible traducir si se desconoce el relato. El contraste entre el catalán y el francés me vino del colegio y los veraneos, y el interés por el inglés con motivo de una estancia de año y medio en Londres a finales de los años '60. A lo cual cabe añadir los siete años de estudio de ruso y dos de chino. Toda mi vida estuvo profundamente marcada por los entresijos de la lengua, la cognición y la cultura. Y luego hay algo importante: creo que es muy difícil hacer una tesis sobre bilingüismo si no eres bilingüe. Me parece que para enfrentarse a una tesis sobre el bilingüismo hay que serlo por adquisición, aunque también según los contextos del aprendizaje, especialmente para entender el relativismo lingüístico y discutir los vínculos del bilingüismo con la cognición y la sensorialidad. Por ejemplo, mi aportación en aquella época fue que se pensaba que el hablar dos lenguas significaba tener dos culturas, y no necesariamente es así: dos lenguas pueden ser una sola cultura. Porque había que distinguir el tercer factor, que era la cognición, y esto generalmente en nuestro territorio no se tenía en cuenta.

En aquella época, la etiqueta de moda en la UB no era etnolingüística, ni etnografía del habla, sino sociolingüística, una 


\section{perifèria}

Número 18 (2), desembre 2013

http://revistes.uab.cat/periferia

interdisciplina que interesaba a lingüistas y psicólogos. Y así coincidí con el Dr. Badia en un congreso en Toronto y también con el Dr. Siguán en diversos seminarios y publicaciones. Una época que culminó en la organización de un seminario en la casa de España de Nueva York sobre el bilingüismo en España en contraste con el de USA. Una cuestión relevante también en aquel país por la pluralidad lingüística de la inmigración y la discusión entre el english only e incorporar el bilingüismo en el aula. Ya cuando era estudiante en UNM, Vera John Steiner me inició en la etnografía del aula en situaciones plurilingües, formas de etnografiar, bien representada en la Universidad Autónoma por los estudios sobre educación de Pepi Soto.

\section{P: Consideramos que es pionera dentro de España de los estudios de género en relación con la cognición y la ideología cultural. ¿Cómo surgió el interés por esta relación? Y, ¿cómo cree que está el campo de estudio en la actualidad?}

B: iCómo no iba a surgir ese interés! Por aquella época, en el mundo académico las mujeres apenas existíamos. Y si miramos las monografías etnográficas éramos siempre parte de capítulos en relación con el matrimonio, la reproducción y la socialización. Justo entrábamos a la academia, éramos poquitas todavía. Y la antropología dio una apertura amplía. En la formación del departamento de Antropología Cultural, Esteva nos abrió las puertas y iquién no recuerda a Josefina Roma, Teresa San Román y Pilar Sanchiz, y otras mujeres de esa primera época! Sin duda todos tenían en mente a Benedict y Mead, y otras antropólogas como Nader o lingüistas como Lakoff, que nos abrían horizontes, impulsadas también por el movimiento de derechos humanos que incorporó en las 


\section{perifèria}

Número 18 (2), desembre 2013

http://revistes.uab.cat/periferia

universidades el territorio del women's studies, al igual que los africanamerican y chicano studies.

En mi formación en UNM cursé una asignatura que se titulaba "Sexual Roles" que impartía Pat Draper. No sé si la conocéis. Ella era parte del equipo que se llevó el profesor Lee de la Harvard University al Kalahari, cuando se realizó el estudio sobre los !Kung Bushmen. Impartía el curso con su marido, Henry Harpending, que era genetista y el énfasis era sobre socialización, pero ya apuntaban en la dirección de superar el capítulo y dar mayor entidad al mundo de las mujeres y también de los niños, todavía hoy encapitulados. En mi investigación de campo me interesaba la vinculación entre bilingüismo y el uso que hacían las mujeres como una expresión de su identidad. De ahí que el primer libro, titulado Antropología de la Mujer (1978), se subtituló cognición, lengua e ideología cultural. Sin duda en aquel momento de auge sobre los estudios de género, la palabra mujer en el título no fue bien aceptada, pero siempre he defendido que los estudios de género, precisamente por tratarse de una construcción, implican tanto la que se hace del hombre como de la mujer, en caso contrario es una contradicción in terminis. Otra cosa es la licencia o la convención de la palabra antropología, que si nos pusiéramos estrictos habría que borrar o reconvertir en Gineantropología o Antropoginelogía. Mujer es una categoría que se puede tratar desde el punto de vista etic y también emic, y eso era lo que daba especificad a lo que quería explicar en aquel libro.

P: Nosotras, las mujeres, continuamente consideramos que nos encontramos en una lucha por una igualdad en el ámbito doméstico, laboral,... etc. Pero todavía observamos grandes desigualdades en los discursos e interpretaciones culturales, siendo esto lo que nos 


\section{perifèria}

Número 18 (2), desembre 2013

http://revistes.uab.cat/periferia

ofrece la realidad del mundo que nos rodea. ¿Cómo considera que debe ser el campo de acción en esta lucha?

B: ¿En la lucha antropológica o en la lucha social?

\section{P: Pues haciendo un mix de ambas, ¿desde la antropología que podríamos aportar a esta lucha?}

B: La antropología es un medio para entender al ser humano pero, como disciplina, su finalidad es hacer buenas etnografías. Cuanto más etnografiemos, $y$ mejores sean los contrastes $y$ matices entre valores y acciones, más se pondrán en evidencia las desigualdades y las exclusiones. Este es nuestro papel profesional. Otra cosa es que queramos implicarnos cívicamente y si nos ofrecen dar una conferencia, o diseñemos un proyecto, incorporar discusiones de género, y más que en el ámbito de la lucha, en el del reconocimiento, al estilo de las propuestas de Axel Honneth.

Yo creo que el gran papel de la antropología es etnografiar; es nuestra vida, es nuestra formación, es lo que nos permite decir que hay cosas que habitualmente no se tratan. Nos damos cuenta de que el género se expresa en espacios en el ámbito doméstico, cómo se vive y comparte cada estancia, e espacios de intromisión y de defensa, lugares neutrales, silenciosos, comunicaciones fácticas, todo aquello que tan bien resume Virginia Woolf de tener habitación propia. Si podemos explicar esto, estamos dando un adelanto importantísimo. O incluso cosas tan tontas como la reversibilidad en las prácticas cotidianas: quién recoge y devuelve las cosas a su sito, quién limpia los grifos o baja la tapa del wáter...., que 


\section{perifèria}

Número 18 (2), desembre 2013

http://revistes.uab.cat/periferia

son marcadores de género permanentes. Poner esto en evidencia, dice mucho.

Esto sería un aspecto, que es en lo más elemental. Pero todavía no tenemos nada sobre el género en las sedes parlamentarias: las relaciones que hay, la frecuencia con la que habla una mujer, cómo orienta un discurso, maneras de interrumpir,... Sin duda saber más sobre todo eso sería una contribución incluso más importante que activar la paridad.

\section{P: Anteriormente ya nos ha mencionado por encima su experiencia etnográfica en el extranjero, pero ¿podría contarnos alguna experiencia de campo fuera de España que le haya marcado en especial en su trayectoria?}

B: Después de mi trabajo de campo de prácticas que hice con Claudio Esteva en Chincheros, siempre traté temas de bilingüismo porque era lo que me preocupaba. Luego hice un segundo trabajo de campo muy interesante, también fue una práctica en América Latina, que fueron dos campañas etnográficas en Quetzaltenango, en el altiplano de Guatemala. Fueron dos veranos también escasos e hice algunas publicaciones especialmente sobre mujeres. Para mí lo que fue realmente importante fueron dos experiencias: el trabajo de campo en Nuevo México y en Carnagie Mellon University. Allí trabajé fundamentalmente con los hispanos no procedentes de México, en la ciudad de Albuquerque, y durante más años en los pueblos de la zona norte del Estado, especialmente en Las Vegas y Gallinas, siempre en relación con los hispanos que poblaron y mestizaron sus vidas y estilos culturales. $Y$ posteriormente incorporé reflexiones sobre los chicanos vinculados al moviendo de derechos humanos. Y me erradiqué en un pueblo en concreto que se llamaba Gallinas, que era un pueblo muy chiquito, 


\section{perifèria}

Número 18 (2), desembre 2013

http://revistes.uab.cat/periferia

chiquito. Del 1975 hasta 1985 alquilaba una casa y todos mis veranos me marchaba en junio, procurando estar allí el mayor tiempo posible. Estuve haciendo diario de campo continuado en Nuevo México y es de donde tengo más material etnográfico que todavía puedo explotar. Siempre digo: "el día que pueda parar, me dedicaré a publicar más sobre Nuevo México", porque es la parte que me interesó más.

Luego, obviamente, al estar tanto allí pues vas cogiendo mucho cariño a todo aquel mundo, te enamoras. Entonces me involucré mucho en el movimiento de derechos humanos, pero asociado a lo que llamé "revitalización cultural". Mis intereses se centraron sobre la construcción de una identidad (siempre en condiciones de bilingüismo y aculturación) desde movimientos de revitalización cultural: fuese religioso -penitentes, bandoleros- o literario implicando consideraciones de género, e incluso de cultural material como el tuning de los coches anglos en un hodroding hispano, y la construcción de carreteras para densificar culturalmente el turismo de paisaje. $Y$ ahí ya apunté una cosa que era nueva: si en general los movimientos de revitalización (Wallace) se fundamentan en lo religioso, en una sociedad con larga tradición literaria, es justamente en la elaboración creativa del discurso donde se centra esa dinámica, y con más potencia en un contexto bilingual y con un spanenglish mediador en el que se involucran desigualdades de género y marginalidad étnica. El trasfondo cultural de discurso era relativo a la cultura hispana de frontera, pero toda la expresividad se canalizaba en spanenglish o directamente en inglés, segunda lengua de escolarización y universidad. Lo cual ejercía un efecto de género nivelador, a la vez que se expandía más allá de los rígidos límites étnicos. Incluso para subvertir estereotipos sexistas tradicionales. 


\section{perifèria}

Número 18 (2), desembre 2013

http://revistes.uab.cat/periferia

Por lo tanto, el discurso era hispano pero la lengua era inglesa. Esta especie de confrontación que se da entre como uno piensa y la lengua que usa para pensar, estos matices eran muy importantes: ver las combinatorias de las dos, en qué circunstancias se dan, por qué, de qué manera...; es decir, estudiar todo ese territorio.

El segundo trabajo, en Carnegie Mellon University, constituyó un cambio radical atendiendo a que los fondos para investigar en América no se renovaron con los cambios en el Instituto de Cooperación Iberoamericana, y opté por abrir una nueva línea de investigación sobre el impacto de las Nuevas Tecnologías que me permitiera llevar alumnos y así realizar sus trabajos de campo ${ }^{3}$. Ciertamente, era un gap: fue pasar del entorno mágico del simbolismo y los chamanes a un entorno red, innovador y con premios Nobel -Simon, Newell ${ }^{4}$-. Y esa nueva tribu era una research university, de tamaño medio, y el campus de Carnegie Mellon reunía todos los requisitos y, el más importante, la aceptación de un grupo de investigación sobre la propia universidad. Ahí estuve como profesor visitante más de medio año y luego de forma intermitente, mientras los doctorandos del grupo permanecieron dos años haciendo trabajo de campo. Los materiales etnográficos sirvieron para presentar las tesis -una sobre la cultura de una facultad de computer science y otra sobre la innovación educativa en red-, publicar artículos y desarrollar asignaturas para el doctorado y el máster

\footnotetext{
3 Título del Proyecto: Diseño cultural, nuevas tecnologías y tradición cultural, diseño, innovación y culturas informáticas. Entidades financiadora: Comité Conjunto Hispano-Norteamericano, Comissió Interdepartamental de Recerca i Innovació Tecnològica de la Generalitat de Catalunya (CIRIT), 19911994.

${ }^{4}$ Se refiere a Herbert Alexander Simon, economista, politólogo y teórico de las ciencias sociales estadounidense, a quien le fue concedido el Premio Nobel de Economía en 1978, y a Allen Newell, investigador en informática y psicología cognitiva. Ambos crearon uno de los primeros programas de inteligencia artificial, el resolutor general de problemas (1957).
} 


\section{perifèria}

Número 18 (2), desembre 2013

http://revistes.uab.cat/periferia

sobre Nuevas Tecnologías y Relaciones Sociales. No hay un salto en el aire, pues introducirme en esa realidad tecnosocial (en una red de innovación académica y social, en el tutor lógico y la inteligencia artificial) fue posible gracias a mi formación en lingüística y cognición, y así enriquecer y contrastar conceptos y realidades etnográficas, que hoy ya son una forma habitual de etnografiar esos impactos y sus contextos sociales.

\section{P. ¿Y cómo pasó del estudio lingüístico a la bioética?}

B: Entre los muchos temas que se trataron en ese proyecto de investigación, una cuestión que se planteaba en el propio campus era relativa a las restricciones que la red, ubicua en las enseñanzas, la investigación y la vida social, podía imponer sobre la sociabilidad. Uno se preguntaba: eso de las nuevas tecnologías, especialmente el correo electrónico ¿̇va a modificar los mecanismos de sociabilidad? Problemas que ahora nos afectan y que en aquel entonces cabía considerar prospectivamente -metodología que me interesaba mucho desde que monté el Instituto de Prospectiva Antropológica en 1983- y también desde la perspectiva de los cambios de valores y actitudes. A mi regreso conecté con el Dr. Esquirol, que organizó un seminario sobre Tecnoética y ahí es donde empecé a publicar sobre estas cuestiones en clave de futuro. Y en ese ambiente también entré en contacto con la Dra. Casado que había promovido un máster de Bioética y Derecho en las Heures (UB) y en este contexto docente empecé a impartir alguna asignatura sobre Riesgo y Cultura, y pronto me incorporé a los proyectos de investigación del recién creado Observatorio de Bioética y Derecho. Proyectos que cubren un amplio espectro de problemas relativos al impacto social, ético y jurídico de los avances biotecnológicos. $Y$ entre éstos, mi mayor contribución ha sido en el 


\section{perifèria}

Número 18 (2), desembre 2013

http://revistes.uab.cat/periferia

proyecto de nanotecnología en el que todavía estamos trabajando y hace dos años presentamos un documento de recomendaciones que se puede consultar en la web del Observatorio de Bioética y Derecho. $Y$, entre las múltiples tareas de este centro de investigación del Parque Científico, el formar parte del Comité de Bioética de la UB y dirigir la revista de Bioética y Derecho, dirección ahora compartida con Maria Casado, una revista indexada.

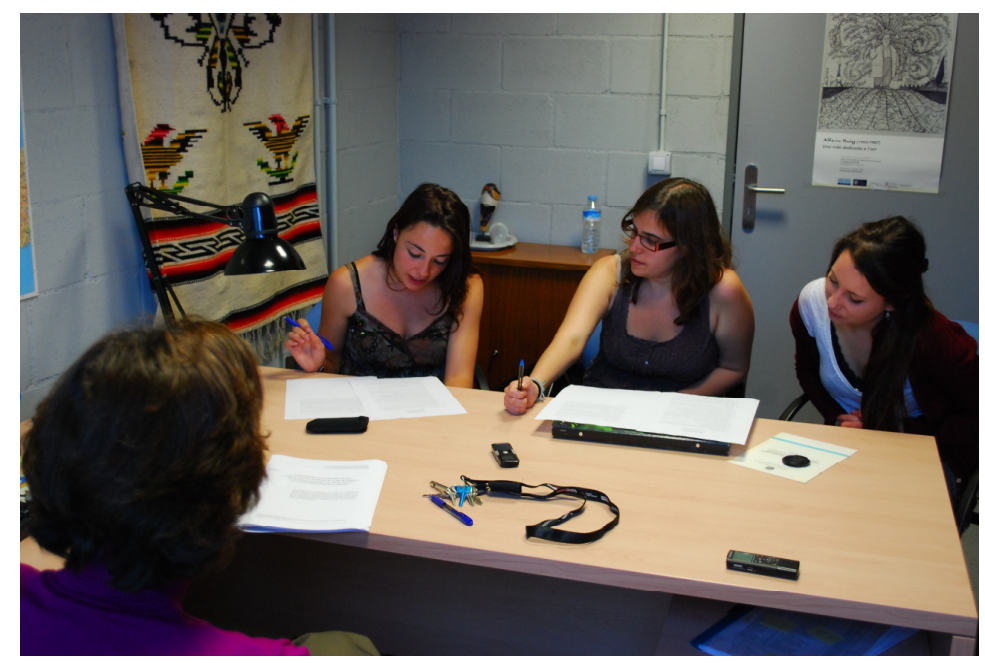

\section{P: En su artículo "Antropología, cultura y bioética" comenta que la} bioética "ocupa ese espacio necesario de reflexión colectiva entre los adelantos científicos y las ideas culturales". ¿Qué peso considera que tiene hoy en día la reflexión cultural en el ámbito científico?

B: A finales del siglo pasado emergen los estudios sociales de ciencia y tecnología, con un precedente en la Filosofía de la Ciencia, aunque marcados por los propios avances en biotecnología y en todas las plataformas tecnológicas, esa "caja negra" denominada por Woolgar y que se extiende a incluso a los estudios de género, como es el caso del "Manifiesto Cyborg" de Haraway. Aunque un poco más tarde que la 


\section{perifèria}

Número 18 (2), desembre 2013

http://revistes.uab.cat/periferia

Sociología de la Ciencia, también ha entrado con fuerza la Antropología Rabinow, Suchmann- especialmente por la etnografía de la que hacen uso por igual todas las disciplinas al investigar laboratorios, centros de investigación e industrias de alta tecnología. Aunque hay que decir que la pionera y quien me impulsó a hacer el cambio hacia Carnegie Mellon fue Laura Nader, con su stuying up en "Reinventing Anthropology", el desafío de investigar en territorios que nos han sido ajenos y que son de alta complejidad, como la ciencia y la tecnología. Quizás fue eso lo que me animó también a dirigir una tesis doctoral sobre la Central nuclear de Vandellós, un reto que implicó conjugar las teorías del riesgo en la construcción de una cultura de la seguridad.

Es en este sentido que entiendo que hacer la Antropología de la Ciencia es muy importante. Todos estos estudios tienen implicaciones éticas relativas a los principios de precaución o el desarrollo de moratorias que impidan daños - afecten la sostenibilidad. En cualquier caso, la relevancia de la antropología es que permite llevar la preocupación bioética más allá de los planteamientos normativos y los protocolos, para situarla en la identificación y la definición de problemas particulares, lo que cabria llamar una bioética situada. Es decir, la ética de cómo se vive el día a día, no la de "pasar un protocolo" y con esto ya hemos actuado correctamente. Por ejemplo, lo que conviene es que el ingeniero, cuando hace un diseño, ya incorpore la ética en la manera de formular el diseño y no que la ética sea como una espada de Damocles. Actualmente, la insistencia en la bioética y en la ética de la investigación ha calado hondo en las instituciones y también en las universidades, y no hay proyecto de investigación que no tenga que hacer un reconocimiento de las implicaciones de su acción sobre los informantes, los materiales sean orgánicos u inorgánicos, de ahí la 


\section{perifèria}

Número 18 (2), desembre 2013

http://revistes.uab.cat/periferia

relevancia de los consentimientos informados, la confidencialidad en pro de la privacidad y el seguimiento adecuado de la información y los materiales.

Y por darle una relevancia mayor a la antropología, en ámbitos donde las interdisciplinaridad es tan amplia -juristas, genetistas, médicos, filósofos, biólogos, químicos, físicos, etc.- la propia configuración de la antropología aporta instrumentos clave para contribuir a la traducibilidad cultural, conseguir que el discurso resultante tenga una semántica coherente, que permita discutir y pueda transitar a su destino final que es el debate informado para con la ciudadanía. Algo complicado en nuestras universidades, en general hechas de "compartimentos estancos" que se llaman departamentos y facultades, a diferencia de las universidades de investigación donde lo que rige no son las áreas de conocimiento, sino los proyectos de investigación que requieren conocimientos de contraste y cruzados para la innovación. Por ejemplo, cuando trabajaba en la Carnegie Mellon University, una de las experiencias más bonitas fue que allí no había departamentos. Allí había proyectos de investigación y en función del proyecto iban lingüistas, antropólogos, tecnólogos... Era el proyecto de investigación el que decía cómo se reunía la gente, no el hecho de la disciplina.

P: Más allá de la academia, la antropología puede jugar un papel muy importante en la resolución de fenómenos sociales. Sabiendo su interés y su experiencia en la aplicación de la antropología, ¿cómo considera que se encuentra la aplicación de la antropología en España actualmente?

B: Ni bien ni mal, inexistente. La antropología académica se ha interesado poco por una antropología que no fuera teórica, de campo e incluso ha 


\section{perifèria}

Número 18 (2), desembre 2013

http://revistes.uab.cat/periferia

recibido con gusto los calificativos de elitista y exótica. Son tan pocos los proyectos que no puedo decir cómo se encuentra la aplicación, aun reconociendo que algún que otro estudio es serio y prometedor - como Pepi Soto y otros que se han dedicado al mundo de la educación. Es Bolonia con su insistencia en la profesionalización que ha hecho mover a los departamentos en busca de empresas, que permitan a los estudiantes acceder a realizar prácticas. Lamentablemente el rendimiento es poco, pero aun así raro es ver el título de Antropología Aplicada, investigación acción, o antropología de la acción en las asignaturas.

En mi caso Cataluña no era mi territorio en otras esferas, pero si lo ha sido desde el punto de vista de la antropología aplicada. Mi único proyecto a largo término de Antropología Aplicada, financiado por una empresa privada, fue sobre seguridad viaria. Nació de un proyecto en Suiza vinculado a la psicología infantil y el tráfico rodado, especialmente orientado a evitar la accidentalidad. Aprendizajes que caracterizaban lo que se denominó un "peatón en rodaje". Hice mucho trabajo de campo en las escuelas -etnografía del aula- así como en calle y plazas. Y así, en equipo, realizamos varios proyectos, visuales -video, spots- y también publicidad y libros de educación que se extendieron de los niños a los jóvenes, lo cual obligó a realizar trabajo de campo en los institutos y en los alrededores de los centros de diversión. La combinatoria teórica sobre la construcción de la accidentalidad tenía aspectos de Mary Douglas, pero también de otros teóricos del riesgo y de las políticas públicas relativas a la conducta cívica. De manera que la idea clave era que cruzar un semáforo en rojo no constituía simplemente una infracción, sino más bien no entender el sentido cívico de la convivencia, vivir en democracia. 


\section{perifèria}

Número 18 (2), desembre 2013

http://revistes.uab.cat/periferia

Fue muy interesante todo el proceso porque el equipo era interdisciplinar, un brainstorming de publicistas, dibujantes, cineastas, pedagogos y antropólogos. Debían plantearse desde los protagonistas de la acción (el niño y la niña, el Winter y la Thur), hasta las acciones ligadas a los referentes culturales, los elementos de los que extraer valores -cascos, bicis-, los escenarios educativos y la construcción del relato. Bueno, fue encantador, divertido y el resultado más que satisfactorio. Los libros que se editaron circularon por las escuelas de Cataluña y en programas escolares por el resto de España, e incluso se incorporó al sistema de educación vial de la $\mathrm{DGT}^{5}$. Nos parecía importante que la educación no quedase sólo en la escuela y diseñamos como llevar esa información a casa, para que retroactuase efectivamente en la iniciación de los niños. Se ideó un carnet por puntos que tenía que firmar finalmente el padre según el rendimiento en las prácticas viarias. Aportamos, asimismo, la educación inversa, en la película de dibujos animados, al ponerse el semáforo en rojo eran los niños que advertían a los padres de la incorrección de cruzar a los padres. Al estilo de lo que hizo Danone años más tarde. El último proyecto fue una exposición de la dirección de tráfico de Cataluña, titulada los Cibercentauros, aquí ya con toda la tecnología más avanzada y futurista. Pero a todo el equipo nos pilló la crisis y el resultado quedó diluido en conferencias públicas y alguna publicación.

\section{P: Viendo sus publicaciones encontramos que abarca una gran variedad de temas, desde la lingüística a la bioética, pasando por el arte o el género entre otros. ¿Cómo ha llevado el hecho de trabajar}

\footnotetext{
${ }^{5}$ Dirección General de Tráfico de España
} 


\section{perifèria}

Número 18 (2), desembre 2013

http://revistes.uab.cat/periferia

con temas tan diversos, teniendo en cuenta que el contexto parece que espera que uno se desarrolle en la carrera especializándose en un tema o ámbito concreto? ¿Le ha sido fácil esta diversidad?

B: Vamos a ver, no ha sido fácil, pero era necesario. Por una razón: porque estaba naciendo la antropología en Cataluña y estábamos construyendo el proyecto de una antropología cultural en la UB. Y necesitaba saber un poco de todo porque a veces tenía que dar asignaturas de Claudio Esteva o de otro profesor que se iba. Esto nos obligó a todos a una docencia diversa, a pesar de que pudimos elegir algún que otro aspecto según nuestra especialización. Yo di generalmente lo que me era más cercano: Antropología Cultural, Etnología de los Pueblos Primitivos (fue también el título de la Agregaduría), Mitología, Magia y Religión, y la asignatura que introduje de Antropología Cognitiva que luego, con el acuerdo de los planes de estudios conjuntos para toda España, se convirtió en Antropología Cognitiva y Simbólica. También había que hacer sustituciones, especialmente para el Dr. Esteva, que tenía que ir a congresos y reuniones, de manera que había que impartir otras asignaturas y etnologías. Quizás lo más importante eran los énfasis: si impartía Pueblos Primitivos, lo hacía como una ecología cultural; y si era Mitología, magia y religión, desde la antropología simbólica. Por lo tanto, la aparente diversidad tenía un trasfondo común que era mi formación en antropología cognitiva y simbólica y también en ecología cultural, disciplina de la cual aprendí mucho sobre riesgo y seguridad. Por lo tanto, no hice más que seguir las exigencias del guión de formalizar la antropología en la universidad española, con mi bagaje personal.

En la flexibilidad influyó mi formación norteamericana, el trasfondo boasiano del mundo de las ideas hacía traspasar las líneas divisorias de las 


\section{perifèria}

Número 18 (2), desembre 2013

http://revistes.uab.cat/periferia

disciplinas: la antropología económica es también antropología simbólica, si no, ¿qué demonios es el dinero? De ahí que mi interés por la tecnología me permitiese ir más allá de la consideración estricta de máquinas y dispositivos para preguntarme sobre los jardines. Una discusión clásica de la antropología entre naturaleza y cultura, y que etnografiando los jardines permite poner en evidencia que son pura tecnología.

\section{P: Ya para terminar nos gustaría saber su visión sobre la antropología en España en la actualidad, ya no la aplicada sino en general. Los resultados de la implantación del grado, si hemos mejorado o hemos empeorado...}

B: Vamos a ver.... Ahora soy profesora emérita, lo cual implica que no vivo el día a día del departamento. Estoy en tribunales y dirijo tesis, imparto un seminario de investigación en el Máster de Antropología y otro seminario de Nanotecnología y riesgo en el Máster de Bioética, y hago tutorías, y lo cierto es que el ambiente de los departamentos no es de alegría. Quizás nunca lo fue, pero Bolonia ${ }^{6}$ ha dejado sin resolver las carencias del pasado y las ha agravado aun más; porque se hizo administrativamente, fue una reforma administrativa, pero no de fondos. Y si a esto sumamos el mundo de la gestión y los aplicativos que nunca acaban de funcionar, el resultado es... la voz del lamento, la queja. Not to mention la crisis. Cuando se inició el Plan Bolonia, el Ministerio me nombró Consejera del Consejo de Coordinación Universitaria. Ahí puede defender la presencia de la Antropología que, según los documentos que recibí en las primeras reuniones, iba a desaparecer. Y ya todos sabemos sobre la movilización de indignados que,

\footnotetext{
${ }^{6}$ Se refiere al Plan de Adaptación del Espacio Europeo de Educación Superior (EEES), conocido como Plan Bolonia por ser la ciudad donde se firmó el acuerdo por parte de los países de la UE.
} 


\section{perifèria}

Número 18 (2), desembre 2013

http://revistes.uab.cat/periferia

promovida por los departamentos, culminó favorablemente. Bolonia fue una propuesta de apertura de la universidad, de flexibilidad y movilidad, que topó con la esclerosis de muchos departamentos y la falta de fondos para dinamizar asignaturas y renovar el profesorado. Se discutieron conceptos y adjetivos, pero siempre remitían al lenguaje administrativo. Se redactaba que había que desarrollar habilidades y destrezas, y ¿si el alumno era zurdo? Se discutía donde situar la Antropología, en Ciencias Sociales o Humanas, discusión vana fruto del compartimento estanco antes mencionado, y de la incapacidad para entender cómo hacer de estas ciencias una profesión. No en vano todo el mundo quiere ser investigador y profesor. Y de la renovación de las asignaturas: los mismos perros con distintos collares; no había presupuesto para renovar el profesorado, ni tiempo para diseñar el contenido de nuevos proyectos docentes. Siempre recuerdo cuando fui profesora visitante en Cornell University, que a los profesores se les daba una subvención especial cuando tenían que renovar o innovar una asignatura, dinero con el que podían ir a visitar otra universidad, biblioteca o simplemente comprar libros y tener tiempo para leerlos. Y me pasó lo mismo en la UCLA, tuve tiempo para discutir con profesores de varios países sobre la diversidad de la ciudad de Los Ángeles.

¿Cuál es la parte positiva o, si se quiere, agridulce? Pues que después de tantos años de bregar por la Antropología, ahora que está sólidamente instalada, hay investigadores y profesores bien formados, de gran calidad, que están batallando para conseguir sus acreditaciones y un lugar en la Universidad a pesar de los batacazos que la crisis esta propinando a todos aquellos (investigadores Juan de la Cierva y otros), que acaban sus contratos y quedan a la espera. Pero aun así tiene todas las cortapisas de estar en facultades de humanidades, a la cola de todas las colas. Para mí, 


\section{perifèria}

Número 18 (2), desembre 2013

http://revistes.uab.cat/periferia

el debate de la antropología es que desde que nace siempre ha tenido que estar luchando para tener presencia en la Universidad, siempre ha tenido que luchar. No es la materia humana, que es buena, sino las condiciones estructurales - si queremos también coyunturales ahora-, que hacen que la antropología no haya podido emerger adecuadamente. Es posible que si nos modernizamos suficientemente y nos convencemos de que nos hemos de reconvertir en universidades de investigación, la antropología tenga un papel distinto. Algunos se animan a abrir nuevos caminos en otros territorios, como por ejemplo el EPIC ${ }^{7}$. Pero lo cierto es que se ralentizan las revistas, se cierran revistas o quedan en stand by, como la Revista de Etnología de Catalunya, a pesar de que el último número que coordiné fue justamente sobre "Innovación, empresa y etnografía". ¿Augurio de algo nuevo o destino fatal?

P: Refiriéndonos ahora al tema de la ética y la bioética, nos preguntábamos si, desde la propia antropólogia española, nos hemos planteado realmente alguna vez la parte ética, el tener un código ético. Ahora tal vez una de las ventajas del nuevo grado puede ser plantear esto, ya que es la primera vez que se envía a alumnos a realizar prácticas, que al fin y al cabo lleva a una profesionalización de la antropología. Pero en cambio, no hace una formación sobre códigos éticos o cuestiones éticas. Ni conocemos que haya ningún código de éste tipo en España.

B: Es muy interesante esto que se está planteando porque, por ejemplo, al venir a hacerme esta entrevista, lo primero que me tendríais que haber

\footnotetext{
${ }^{7}$ EPIC, the Ethnographic Praxis in Industries Conference: http://epiconference.com/node
} 


\section{perifèria}

Número 18 (2), desembre 2013

http://revistes.uab.cat/periferia

hecho es darme un papel de consentimiento informado. Consentimiento para grabar, fotografiar y publicar. Ya llevamos en antropología varios años hablando de consentimiento informado en relación con los informantes, y la discusión de la autoría está profundamente relacionada. Desde el Comité de Bioética de la UB no llegan todos los proyectos de investigación: inicialmente llegaban desde la biotecnología y la medicina, y progresivamente desde la psicología y otras ciencias sociales y humanas. La experimentación ha sido el punto de partida (sea por el manejo de muestras orgánicas o biobancos, y otras pruebas) hasta llegar a la gestión de las relaciones humanas y sus implicaciones en el ámbito de la confidencialidad y la privacidad. Hasta hace poco era frecuente que los protocolos a rellenar fuesen universales para la investigación en general. Pero, ¿qué sentido tenía proponer un protocolo con preguntas sobre elementos orgánicos si la investigación era de ciencias humanas? De ahí que ahora se ha realizado un nuevo anexo específico para las ciencias sociales y humanas, y que hemos elaborado con el fin de recoger aspectos que pueden ser problemáticos respecto a la privacidad y la confidencialidad respecto al informante y el registro de los datos, así como el seguimiento, la donación, la conservación y la destrucción de los mismos. Todo esto queda amparado por este sistema. Entonces el investigador sabe que tiene que pasar por el código ético. E, incluso, si tiene dudas razonables sobre temas sensibles, puede consultar con el comité.

P: La impresión que tenemos es que hay formación para hacer trabajo de campo pero que salen los problemas cuando tú estás solo haciendo el trabajo de campo. Te los encuentras y cada uno los resuelve como buenamente puede. 


\section{perifèria}

Número 18 (2), desembre 2013

http://revistes.uab.cat/periferia

B: Y al final dependerá de sus propios valores, de la integridad ética en el proceso investigador.

\section{P: Nosotras, por ejemplo, no tenemos un marco de referencia, ya no digamos de formación, sino de un código ético que sepamos que esté allá y que nos pueda servir.}

B: $Y$ hay cosas que se han de vigilar, por ejemplo el hecho de sacar fotografías. Captar imágenes, por ejemplo, siempre fue un tema sensible que remitía a robar el alma y que ahora, con la facilidad de los dispositivos fotográficos, no hay cortesía ninguna sobre la imagen del otro. Es un tema clave en antropología visual; no puede ser que no haya un consentimiento informal. Yo recuerdo un día que iba por la carretera austral -aquello que dicen los chilenos, "donde el demonio perdió el poncho"-, me encontré con dos tremendos carros de troncos, y tres carreteros vestidos al uso, lo cual me sedujo para bajar del coche y sacar la foto. Era un paisaje precioso, con esas luces de tarde, un silencio fantástico. $Y$ me acerqué preguntando si podía tomar una fotografía. Me contestaron que no. iMe quedé tan parada...! De entrada lo pregunté, que fue una cosa que hice bien, pero me sorprendió tanto que me dijesen que no, que les pregunté porque no querían que les sacase una fotografía. Me contestaron que no porque se debía pedir permiso al ayuntamiento. Ya habían pasado antropólogos y les habían avisado que sus imágenes eran propiedad privada. Y siempre que he preguntado a otros investigadores si había tal permiso, la respuesta ha sido no.

Ya no digamos otras dudas largamente discutidas sobre el pagar o no a los informantes. Y sobre todo eso que se habla ahora de cómo hacer el retorno. Una vez que has pasado por un lugar haciendo trabajo de campo ya no es 


\section{perifèria}

Número 18 (2), desembre 2013

http://revistes.uab.cat/periferia

lo mismo, y eso se ha de cuidar mucho. Esto no nos lo hemos planteado nunca: una vez has hecho el trabajo, ¿cómo se lo llevas? ¿Se puede ayudar, no se puede ayudar? Cuando haces la antropología "en casa" puede ser menos relevante, pero cuando sales no es lo mismo. Pero yo creo que incluso en la antropología hecha "en casa" también es muy importante. Podemos hacer una oferta bien interesante.

\section{P: Quizás los americanos lo tienen mucho más trabajado que nosotros, porque tienen un código...}

B: Research integrity son las palabras que hoy se usan para actuar acorde a los requerimientos de los derechos humanos y la profesionalidad responsable. No hay que olvidar que la previa a la declaración de los Derechos Humanos de la Unesco (1948) fue antropológica, el Statement on Human Rights (1947) y en ello contribuyó Herskovits, de manera que es un tema casero. Yo siempre digo eso, que a veces la gente no lo recuerda, que la antropología tiene un recorrido muy importante.

\section{P: Por nuestra parte ya está. Si quieres añadir algo más que creas conveniente, adelante.}

B: No me habéis preguntado por qué me dedico a estudiar jardines. Bueno no me habéis preguntado nada muy personal, pero os explico: mi marido era un forofo de los árboles y los fines de semana nos íbamos a la Garrotxa y allí limpiábamos el bosque. $Y$ entre esto del bosque y el jardín - que siempre tuve el jardín en casa desde pequeñita -, pues me interesó el tema de los jardines, como un tema asociado a la relación naturaleza-cultura. Entonces comencé a trabajar diciendo que el jardín es lo más tecnológico 


\section{perifèria}

Número 18 (2), desembre 2013

http://revistes.uab.cat/periferia

que tenemos bajo la apariencia más maravillosa de naturaleza. Y es por ahí por donde lo he encaminado. Ahora acabo de venir de un Congreso en Zúrich, donde he presentado un trabajo bajo el título "De la perfección natural a la biocompatibilidad", porque el concepto de jardín siempre se vincula a la construcción de perfección natural. Desde Bacon hasta la actualidad. Entonces trabajo esto a través de los improvers en jardinería, hasta llegar a la biocompatibilidad nanotecnológica. Y ahora me marcho el viernes a Serignac, que hay un seminario dedicado a jardines y hablaré de jardines catalanes. ¿Conocéis este artículo: "La construcción de la catalanidad a través de los jardines"? Trata de cómo podemos reseguir la identidad catalana a través de la construcción de los jardines. Este me lo publicaron en inglés en un libro que se titula Iberian cities, "Ciudades Ibéricas", que se dedica fundamentalmente a Barcelona. Entonces me pidieron un artículo, porque sabían que trabajaba con la identidad catalana y los jardines.

Previo a esto ya había hecho algo sobre el imaginario étnico en Cataluña. También me ha interesado la antropología de proximidad, en mi caso la catalanidad vista desde diferentes perspectivas, especialmente la identidad. Desde la construcción imaginaria de la catalanidad hasta la expresión de la misma a través de los jardines. Y si me preguntáis como he accedido a muchas de esas casas y he visitado sus eixidas ${ }^{8}$ fue gracias a mi padre que era médico y me llevaba a visitar esas familias. Ahí conocí a muchas de mis informantes del área de Sabadell, donde me planeé el tema de la fertilidad y por qué era tan baja en el mundo obrero. Se trata de un tema interesantísimo, porque venían mujeres inmigrantes y tenían seis, siete hijos. ¿Cómo hacían las mujeres catalanas para tener solo un hijo? Ellas me

\footnotetext{
${ }^{8}$ Nombre que recibe el patio trasero de las casas obreras catalanas de principios del s.XX
} 


\section{perifèria}

Número 18 (2), desembre 2013

http://revistes.uab.cat/periferia

explicaron como lo hacían, cómo compartían el quehacer doméstico entre vecinas y también como se distribuía la vida en la cotidianeidad. El mundo de las eixidas que era un mundo femenino, una habitación propia que tenía seguramente su complemento en las andronas (la palabra viene de andros, de hombre) o lugar posterior de la casa, donde los hombres se reunían para hablar y fumar. Luego ya cuando viene la industrialización empiezan a cerrarse los patios posteriores y forman la eixida, que pasa a ser un espacio femenino.

Era también un lugar donde se producía ese fenómeno que llamamos inversión simbólica: si dentro de la casa todo era convención, fuera se permitían andar desarreglado, eructar, echarse pedos, colgar la ropa íntima, un rincón para el estiércol, el basurero, y el gallinero... Todo aquello que remitía a la libertad de la naturaleza, sin olvidar el curanderismo, pues ahí se reunían los cuatro elementos: el fuego, el agua, la tierra y el aire. Es interesante esto, ¿eh? Esto es la etnografía, abrirnos a realidades complejas que han permanecido en lo tácito y nos enseñan mucho de la capacidad de imaginar y compartir.

\section{Pues nada más. Muchas gracias por todo.}




\section{perifèria}

Número 18 (2), desembre 2013

http://revistes.uab.cat/periferia

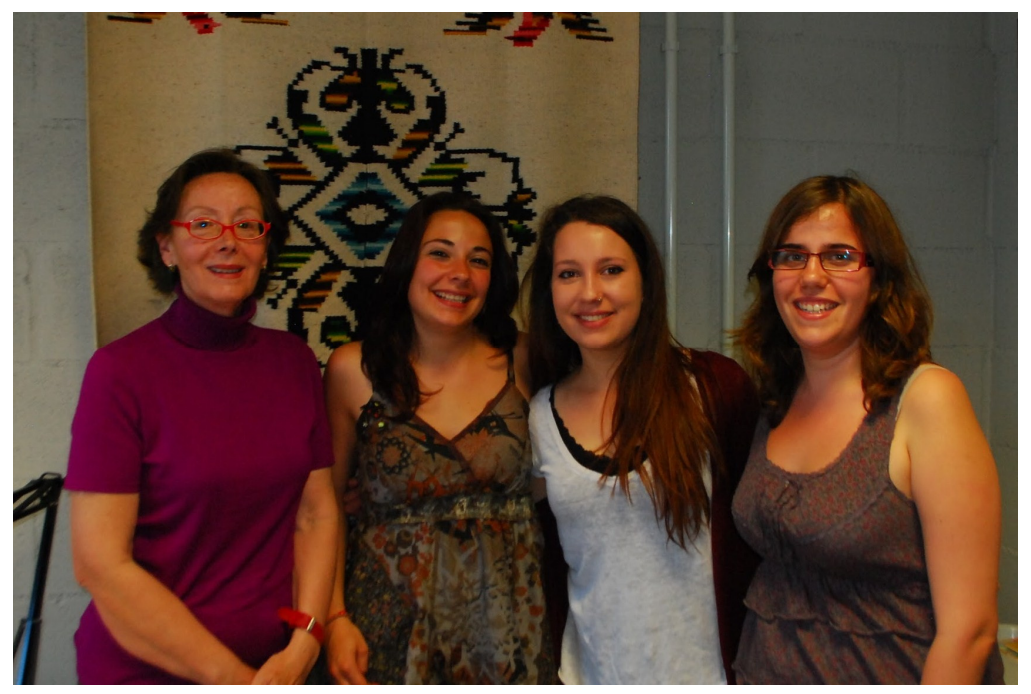

Maria Jesús Buxó, Carolina Villar, Elena Amunárriz y Carla Brito 